\title{
GPS Strain Rate and Seismic Activity Before the Ludian Earthquake (Ms 6.5), Northeast Yunnan, China: New Implications for Eastward Chuan-Dian Block Extrusion
}

\author{
Zhe $\mathrm{Su}^{1, *}$, Erchie Wang ${ }^{2}$, Gang Wang ${ }^{3}$, and Chun Fan ${ }^{4}$ \\ ${ }^{I}$ Key Laboratory of Crustal Dynamics, Institute of Crustal Dynamics, China Earthquake Administration, Beijing, China \\ ${ }^{2}$ State Key Laboratory of Lithospheric Evolution, Institute of Geophysics and Geology, Chinese Academy of Sciences, Beijing, \\ China \\ ${ }^{3}$ College of Earth Sciences, Chengdu University of Technology, Chengdu, China \\ ${ }^{4}$ School of Energy Resources, China University of Geosciences, Beijing, China
}

Received 18 January 2016, revised 9 February 2016, accepted 15 February 2016

\begin{abstract}
We characterized E-W shortening crustal deformation using GPS measurements and an earthquake focal mechanism solution to estimate conditions before the Ms 6.5 Ludian earthquake of 3 August 2014 (16:30, UTC+8). A series of NW-SE striking transpressive faults are distributed outside the Chuan-Dian Block. They accommodated the E-W shortening and N-S stretching in this region resulting from Chuan-Dian Block outward expansion. The displacement velocity field about the eastward, faultnormal slip rate and the vertical component are also examined. The results show that they share a similar rate change at the Anninghe, Zemuhe, Puxionghe, Jiaojihe, and Baogunao-Xiaohe faults. Among these faults, the maximum thrusting slip rate of the Baogunao-Xiaohe fault is less than $4 \mathrm{~mm} \mathrm{yr}^{-1}$. The slip rate change may represent a transition from lateral translation into a vertical thrusting movement. Furthermore, counterclockwise rotation also plays an important role in absorbing the E-W shortening. Relative to the inner zone, the outer Chuan-Dian Block together with the Daliang Shan fault zone represent the development of a new deformation area. A prediction could be made that the Daliang Shan fault zone will eventually replace the east boundary fault role of the Anninghe-Zemuhe-North Xiaojiang fault due to Chuan-Dian Block continuous outward expansion.
\end{abstract}

Key words: Ludian earthquake (Ms 6.5), Chuan-Dian Block, Daliang Shan fault zone, GPS strain rate, Focal mechanism solution analysis Citation: Su, Z., E. Wang, G. Wang, and C. Fan, 2016: GPS strain rate and seismic activity before the Ludian earthquake (Ms 6.5), northeast Yunnan, China: New implications for eastward Chuan-Dian Block extrusion. Terr. Atmos. Ocean. Sci., 27, 837-851, doi: 10.3319/TAO.2016.02.15.01(TT)

\section{INTRODUCTION}

On 3 August 2014 at 16:30 p.m. (UTC+08:00), a Ms 6.5 earthquake occurred in Ludian County, northeast Yunnan Province, China. Although not very large in magnitude, the Ludian earthquake has become the second worst natural disaster (617 deaths) after the Wenchuan earthquake (Mw 7.9). One of the active faults in this region, named the Baogunao-Xiaohe fault (Xu et al. 2015), is the most likely to have triggered this earthquake. Initially after its occurrence, earthquake catalogs worldwide [e.g., Global Centroid-Moment-Tensor (CMT), USGS NEIC, GFZ, CENC; Fig. 1b] interpreted it as a pure strike-slip faulting event (actually, a conjugate set of strike-slip faults would most likely result

\footnotetext{
* Corresponding author

E-mail:szhe1230@126.com
}

in the Ludian earthquake; Fig. 1b). However, the aftershock distribution gives us another interpretation (cyan dots at depth; Fig. 1b). The seismogenic structure must also pose a thrusting sub-motion except for strike-slip shearing (see the black beach balls in Fig. 1b; the aftershock data is from Zhang et al. 2014). In that case a transpressive fault resulted in the Ludian earthquake. We are interested in investigating the tectonic background that led to this Ludian earthquake.

The ongoing collision between the India Plate and the Eurasia Plate occurs mainly along the northwest and southeast corners of the Tibetan Plateau. These two collision horns are named the Western and Eastern Himalaya syntaxis (WH and EH, respectively; see the micro-plot in Fig. 1a; Molnar and Tapponnier 1975; Tapponnier et al. 1986, 2001). To the east, the southeast margin of the Tibetan Plateau moves laterally along the $2000 \mathrm{~km}$ Xianshuihe-Xiaojiang 
fault system (Molnar and Tapponnier 1975; Tapponnier et al. 1986; Molnar and Dayem 2010). Several second-order blocks are also involved in this motion, which could make them move away from the collision front (King et al. 1997; Chen et al. 2000; Shen et al. 2005; Fig. 1a). The ChuanDian Block (CDB) is among them. GPS measurements have shown that the Chuan-Dian rhomboid fragment experiences a rapid southeastward extrusion at a rate of $5-12 \mathrm{~mm} \mathrm{yr}^{-1}$ (e.g., Chen et al. 2000; Shen et al. 2005). Due to its oblique movement, the lateral motion could simply be decomposed into two sub-components: southward and eastward. Of the two, the southward motion is believed to have been absorbed by the left-lateral shearing movement along a series of $\mathrm{N}$ S-striking strike-slip fault systems within the CDB (Wang et al. 1998), e.g., the West and East Xiaojiang, Puduhe, and Lvzhijiang faults (e.g., He et al. 2009). However, the dynamic accommodation for the eastward sub-motion remains controversial. One argument speculates that the differential clockwise rotation produced by Sichuan basin counterclockwise rotation dragging should play an important role (Xu et al. 2003; Shen et al. 2005; Wang et al. 2014). The second hypothesis considers that the eastward expansion may simply be explained by vertical crustal shortening deformation (He and Ikeda 2007; Chen and He 2008; Wen et al. 2011, 2013). For example, it has been reported that a large thrusting component exits along a set of NW-SE strike-slip faults (He and Ikeda 2007; Chen and He 2008; Ran et al. 2008), e.g., the eastern boundary fault of Yuexi Basin. With this exception the Gongga Mountain (7556 m) uplift and the Xiaoxiang-Ling range $(4500 \mathrm{~m})$ are also believed to have resulted from the E-W shortening (Chen et al. 2008). Some researchers believe that the eastward movement does not occur in the upper crust, but is mainly concentrated in the deeper middle and lower crusts (Southeast Tibet, e.g., King et al. 1997; Schoenbohm et al. 2006; and East Tibet, e.g., Kirby et al. 2000, 2008; Kirby and Ouimet 2011).

GPS has become one of the most important geodetic tools for studying crustal deformation (Dixon 1991; Segall and Davis 1997; Thatcher 2003). A GPS network has been established since the early 1990s along the southeast margin

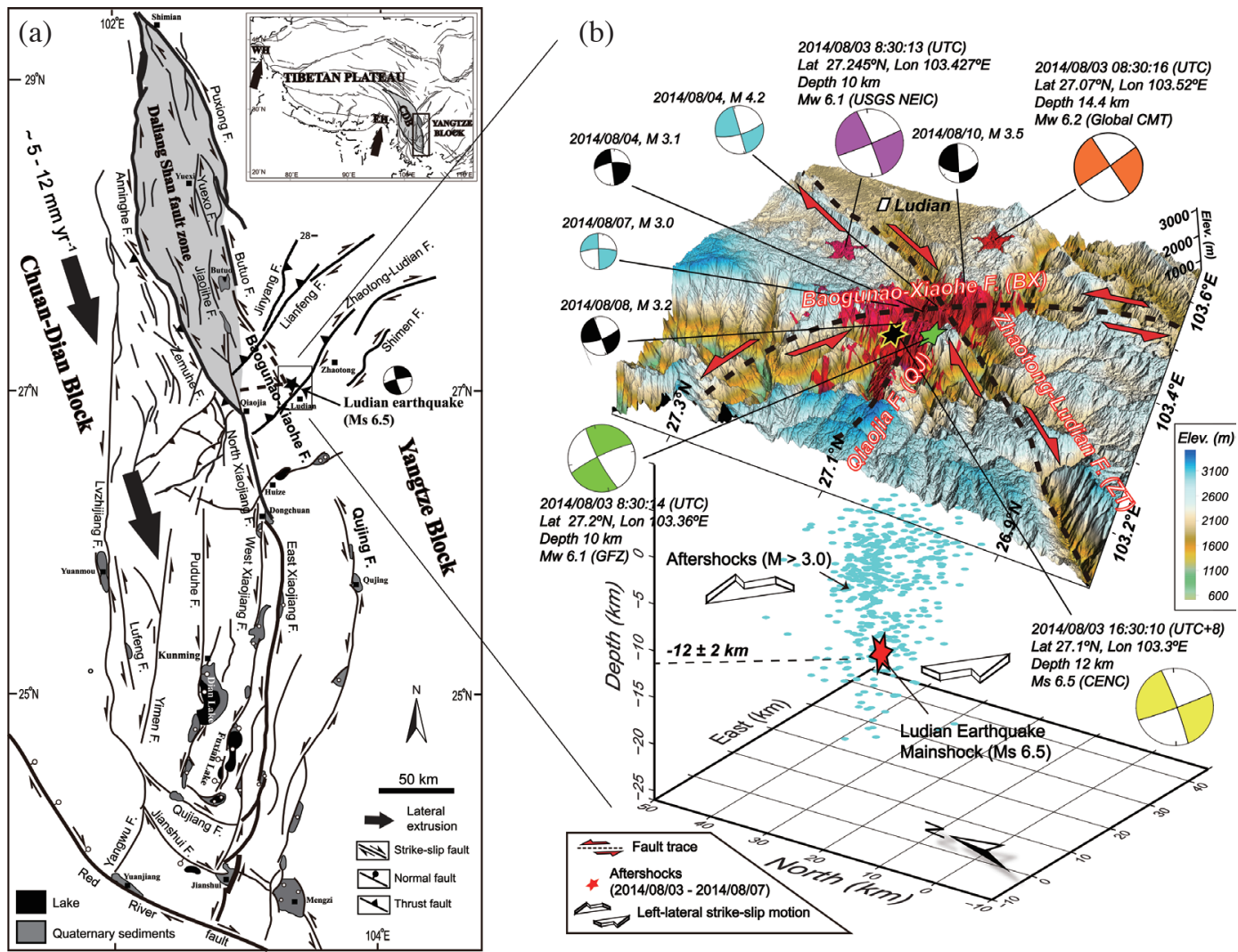

Fig. 1. (a) The tectonic framework for the southeast margin of the Tibetan Plateau (modified from Wang et al. 1998). The right upper illustration displays the location of this study. EH: Eastern Himalayan syntaxis; WH: Western Himalaya syntaxis. The beach ball represents the focal mechanism solution of the Ludian earthquake's main shock (sourced from the Global CMT catalog; see Data and Resources). (b) Focal mechanism solutions of the main shock and aftershocks of the Ludian earthquake. The orange, blue, green, and yellow beach balls are sourced from different earthquake catalogs worldwide (see Data and Resources). The aftershock data was collected from Zhang et al. (2014) and had a time span from 3 August 2014 to 7 August 2014. The black star at a depth of $12 \pm 2 \mathrm{~km}$ indicates the epicenter of the Ludian earthquake. The two black dotted lines represent the positions of the conjugated fault system on the surface: the NW-SE-striking BX fault and the NE-SW trending Zhaotong-Ludian (ZT) fault. (Color online only) 
of the Tibetan Plateau. Until now, it has been composed of more than 100 continuous and campaign GPS recording stations in that region. Previous results using satellite positioning have mainly revealed the interseismic horizontal velocity field within the seismogenic portion of the lithosphere of the Tibetan Plateau (King et al. 1997; Chen et al. 2000; Zhang et al. 2004; Gan et al. 2007). Research on vertical deformation is rare (an exception is Liang et al. 2013). In the following section we attempt to quantify the possible thrusting deformation through GPS measurement analysis (horizontal GPS velocities are from Gan et al. 2007; vertical GPS velocities from 1999 to 2009 are from Liang et al. 2013) and a focal mechanism solution for historical earthquakes (from the Global CMT earthquake catalog from 1976 to 2015).

\section{SEISMOTECTONIC SETTING}

The southeastern Tibetan Plateau and its adjacent area to the south include two large rhombic-shaped active areas, the aforementioned CDB and the Daliang Shan (DLS) crustal fragment (Fig. 2). The CDB is defined by the XianshuiheXiaojiang fault in the northeast and the Red River fault in the southwest (Huchon et al. 1994; Wang et al. 1998; Su et al. 2012). The northern half of the CDB contains a conjugate set of strike-slip faults, which together accommodate this fragment's lateral extrusion from the N-S compression region to the west (directly north of the corner of the India indenter), as indicated by left- and right-lateral strike-slip faults (Wilson et al. 2006; Su et al. 2012). To the south, however, almost all of the strike-slip faults are arranged with a N-S striking. Different from those conjugated fault systems distributed to the north, these are mostly left-lateral strike-slip faults. GPS measurements have shown that internal sub-blocks surrounding SE Tibet are experiencing a clockwise rotation that circles around the EH (King et al. 1997; Shen et al. 2005; Gan et al. 2007; Liang et al. 2013).

The Ludian earthquake occurred to the east of the Xianshuihe-Xiaojiang fault system between the Chuan-Dian rhomb block and the Yangtze Block (Wang et al. 1998; Deng et al. 2003; Xu et al. 2003; Zhang et al. 2003; Zhou et al. 2003; Shen et al. 2005; Ren et al. 2010). The position is located at the south margin of the DLS fault zone (Fig. 2). The latter is also a rhombic fragment composed of a series of NWN-SES-striking left-lateral strike-slip faults. They are the Jiaojihe, Butuo, and Puxionghe faults from west to east (Xu et al. 2003). The Puxionghe fault is one of the largest among them (Fig. 2). It forms the eastern splay and may consist of several strand faults. South of Shimian County, these faults cut the rocks of the South China fold and thrust belts on both sides of the faults (Wang et al. 1998).

The N-S-striking Anninghe fault consists of several parallel strands and forms the western splay of the DLS. Its curved trace parallels the structural grain of a Cenozoic foldthrust belt. Farther south, the southeast-striking Zemuhe fault cuts obliquely through the Cenozoic fold belt and connects to the south end of the Anninghe fault at Liangshan City (originally named Xichang City; Fig. 2). The Zemuhe and Jiaojihe faults join at Qiaojia and then follow the Jinsha River southward to form the northern end of the Xiaojiang fault segment. Farther to the south, a set of NE-SW right-lateral strike-slip faults, e.g., the Lianfeng-Jinyang fault and the Zhaotong-Ludian fault, bound the DLS's southern margin (Fig. 2).

Before the Ludian earthquake this seismic zone and its neighboring areas have not experienced any destructive earthquake with a magnitude of more than 7.0. However, at least eight earthquake clusters, consisting of small to moderate earthquakes, have been distributed across SE Tibet (seismic zones I to VIII; Fig. 2). The locations of the earthquake

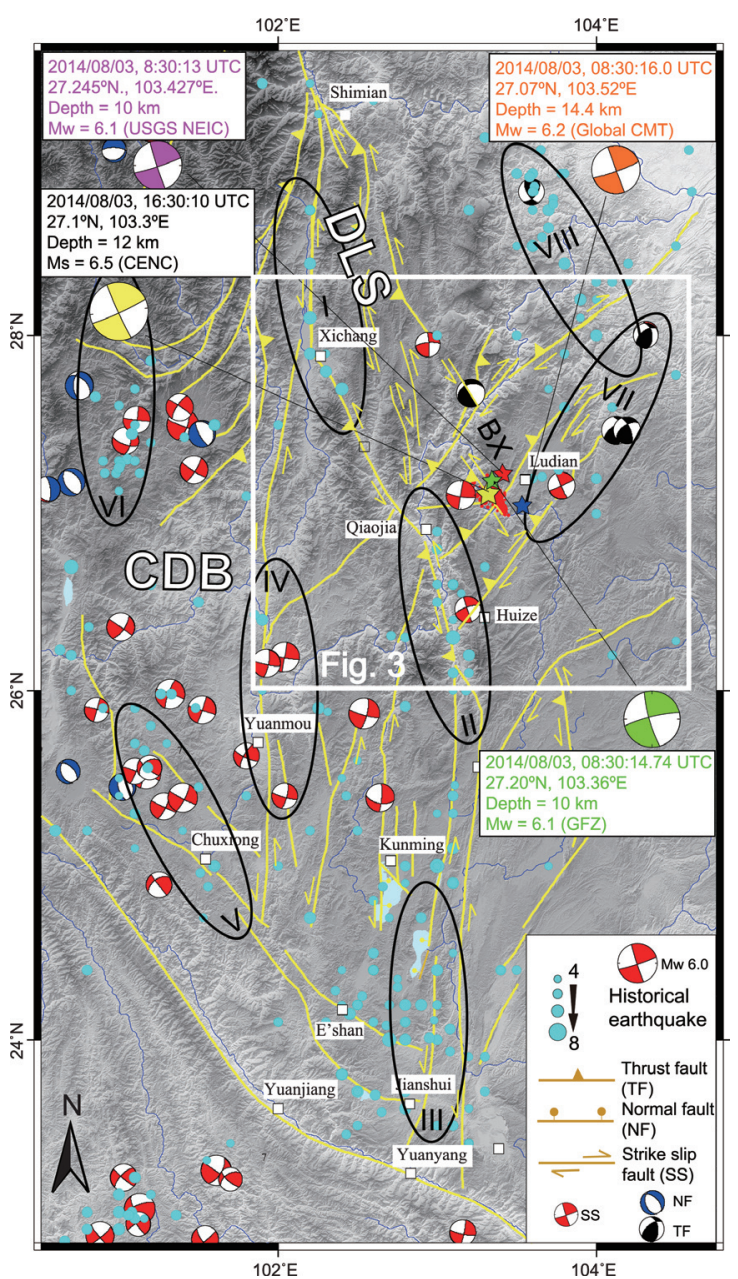

Fig. 2. Historical earthquakes of SE Tibet. Focal mechanism solutions for the Ludian earthquake main shock are displayed with the same colors as displayed in Fig. 1b. The smaller focal mechanism solutions (FM), colored as blue, red, and black in the background (1976 - 2015; sourced from the Global CMT seismic catalog), stand for normal extension, strike-slip shearing, and thrusting earthquake events, respectively. The brilliant blue dots are used to show historical earthquakes in this region (1500 - 2011; China Earthquake Data Center). CDB: Chuan-Dian Block; YZB: Yangtze Block; DLS: Daliang Shan fault zone; BX: Baogunao-Xiaohe fault; QJ: Qiaojia fault. (Color online only) 
groups are consistent with those mapped active fault traces. Most of their associated focal mechanism solutions indicate a nearly pure strike-slip faulting movement (red beach balls in Fig. 2).

The stress domain within and outside the CDB appear to differ from each other. Some earthquake focal mechanism solutions show an extension deformation in the CDB (blue beach balls in seismic zones V and VI; Fig. 2). Farther to the east a series of thrusting earthquake events occurred in seismic zone VIII (black beach balls in Fig. 2). These quakes were distributed mainly along the easternmost seg- ment of the Huize-Yilang fault and the southern part of the Puxionghe fault. These faults all pose an over thrusting submotion, e.g., Zhaotong-Ludian (Wen et al. 2011), Zemuhe (Ren 1994), Anninghe (He and Ikeda 2007), Puxionghe (Chen and He 2008), and Lianfeng-Jinyang fault (Wen et al. 2013).

\section{FOCAL MECHANISM SOLUTION ANALYSIS}

Several earthquakes struck the neighboring regions of Ludian County before the Ludian earthquake (Fig. 3a).

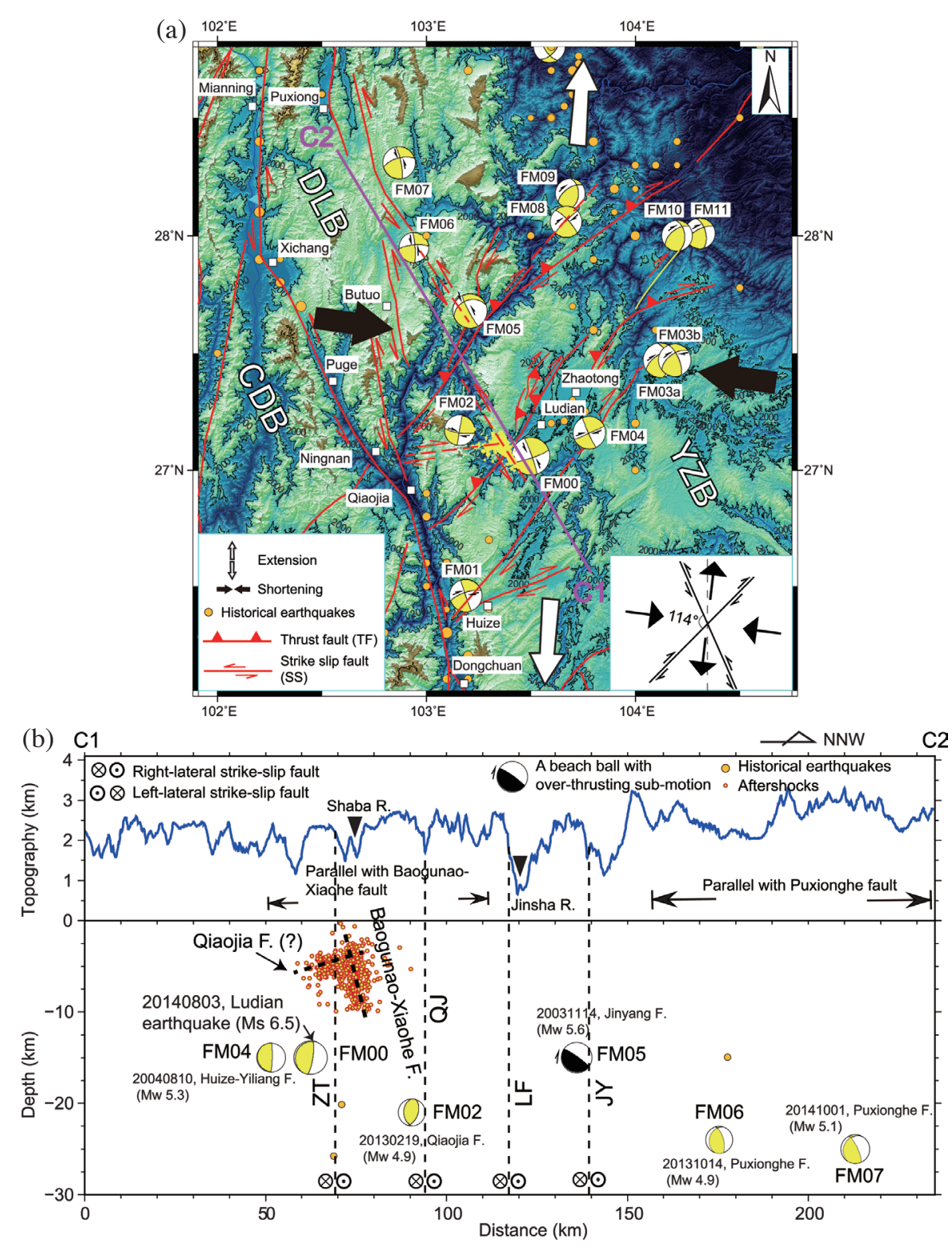

Fig. 3. (a) Focal mechanism solutions of earthquakes surrounding the Ludian earthquake epicenter. Small arrows in each beach ball indicate possible coseismic displacement. Single arrows are used for standing over-thrusting movement. Double arrows display a strike-slip shearing movement along a fault plane. The two black bold and white arrows stand for E-W shortening and N-S extension. The right-bottom illustration shows the intersection angle between these conjugated strike-slip faults. CDB: Chuan-Dian Block; DLS: Daliang Shan fault zone; YZB: Yangtze Block. (b) Profile $\mathrm{C} 1 \mathrm{C} 2$ cuts from SE to NW, parallel to the striking direction of the seismogenic structure of the Baogunao-Xiaohe fault. ZT: Zhaotong-Ludian fault; QJ: Qiaojia fault; LF: Lianfeng-Jinyang fault. (Color online only) 
An earthquake of Mw 5.2 occurred in Huize County on 5 August 2005. This is over $\sim 70 \mathrm{~km}$ away from the Ludian earthquake epicenter to the southwest. The focal mechanism solution displayed a nearly pure strike-slip shearing movement (FM01 in Fig. 3a). Considering that the Huize fault is also a nearly east-west-striking structure, we attribute the FM01 earthquake event to triggering by the Huize fault. Farther to the north another earthquake of Mw 4.9 occurred on 19 February 2013, east of Qiaojia Town. The earthquake epicenter is situated at the western bank of the Niulan River, a second-order tributary of the Jinsha River. The focal mechanism of the Qiaojia earthquake shows a right-lateral strike-slip moving event (FM02 in Fig. 3a). This may be consistent with the nearly E-W extending Qiaojia fault (Xu et al. 2015). The Qiaojia fault is considered to extend to the east and joins with the Baogunao-Xiaohe fault.

Farther to the north a series of earthquakes (FM05, FM06, and FM07) occurred along the NWN-SES-striking Puxionghe fault. Other faults, such as the Shimian, Butuo, and Jiaojihe faults, have not experienced any earthquakes since 1976 (the Global CMT earthquake catalog began in 1976). Only the FM05 beach ball shows a compound movement composed of strike-slip shearing together with a minor sub-component of thrusting (Fig. 3a). This is not seen in the FM06 and FM07. These earthquake focal mechanism solutions demonstrate that the Puxionghe fault is a left-lateral strike-slip fault with a minor thrusting sub-motion. Together with the Butuo, Shimian, and Jiaojihe faults, this set of NWN-SES-striking faults is arranged into a left-lateral en echelon structure (Fig. 3a).

The distribution of aftershocks indicates a west-east striking fault plane at a depth of $4-6 \mathrm{~km}$ (Fig. 3b). This meets the seismogenic fault of the Baogunao-Xiaohe fault with a conjugated pattern. Previous researchers believed that the right-lateral NE-SW striking Zhaotong-Ludian fault should be another conjugated fault with the possibility of causing the Ludian earthquake (e.g., $\mathrm{Xu}$ et al. 2015). We propose another hypothesis, that the E-W arranged aftershock group (yellow dots in the $\mathrm{C} 1 \mathrm{C} 2$ profile; Fig. $3 \mathrm{~b}$ ) is consistent with the E-W striking Qiaojia fault on the surface (red dotted line in the Fig. 3a), not the Zhaotong-Ludian fault.

\section{GPS RATE CHANGE}

The strain rate field reveals local strain accumulation rates and their possible connection to the seismic hazard potential (Ward 1994). Likewise, the strain accumulation for the 2014 Ludian earthquake should also come from its interseismic deformation. Based on the same principle we derived a dataset of averaged GPS velocities (7-year averaged horizontal velocities from 1998 and 2004; Gan et al. 2007; 10-year averaged vertical measurements from 1999 to 2013; Liang et al. 2013) to quantify the state of pre-seismic strain accumulation. A total of 46 GPS horizontal vectors from Gan et al. (2007) and 37 vertical velocities from Liang et al. (2013) were applied in our study area. These velocity vectors are referenced with the fixed Eurasia Plate.

The main motivation for this study is to investigate whether a set of NW-SE or NWN-SES strike-slip faults outside the CDB can be considered a sub-component of overthrusting. Therefore, we draw three NE-SW cross sections that cut across the northern, central and southern part of the fault system. Although they are not perfectly perpendicular to every fault's striking direction, such as the N-S striking Anninghe fault, we can apply the slip-rate change tendency along the profiles to explore any possible vertical deformation. We designed the following strategies for this research. We first checked whether the eastward slip rate of the profile changes when meeting with the NW-SE-striking faults, because such an eastward subcomponent might be transferred into a vertical over-thrusting motion along these boundary faults. We then directly listed the change in the vertical velocities across the faults. The horizontal velocities are then decomposed into two directions: fault-parallel and fault-perpendicular. We use the fault-parallel change to approximately stand for the differential strike-slip rate between the hanging wall and foot wall of a fault. Although the fault-normal slip-rate change is not equal to the dip-slip of the fault, the movement tendency should be similar.

\subsection{Eastward Velocity Change}

Along the northern $\mathrm{AB}$-crossing transect, the velocity sub-component moving to the east was not changed significantly while cutting across the Anninghe fault $\left(<0.1 \mathrm{~mm} \mathrm{yr}^{-1}\right.$; Fig. 4). We simply speculate that the northern segment of the Anninghe fault may not have had much of a vertical subcomponent. Farther to the east, the eastward subcomponents

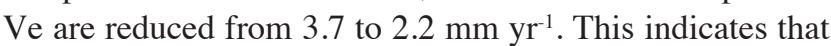
the velocity difference of $1.5 \mathrm{~mm} \mathrm{yr}^{-1}$ could be accommodated by the Puxionghe fault thrust motion.

The middle CD section cuts across four faults: the Zemuhe, the northern part of Jiaojihe, the southern segment of Butuo and Puxionghe from west to east. From stations H102 to $\mathrm{H} 095$ the eastward velocity decreases by $\sim 1.3 \mathrm{~mm} \mathrm{yr}^{-1}$ to the east (Fig. 4). We deduce that the minimum vertical rate of the Zemuhe fault is $\sim 1.3 \mathrm{~mm} \mathrm{yr}^{-1}$. Both the Jiaojihe and $\mathrm{Bu}-$ tuo faults are located in the region between H100 and H094. Therefore, it is unclear how a rate change of $1.4 \mathrm{~mm} \mathrm{yr}^{-1}$ would be partitioned between them. On the southern segment of the Puxionghe fault, the eastward sub-component velocity suddenly drops by $\sim 4.7 \mathrm{~mm} \mathrm{yr}^{-1}$. We know that the Puxionghe fault is an active thrusting fault, documented by FM05 (see the FM05 beach ball in Fig. 3). With the other two recent earthquakes along this segment, we speculate that the southern segment of the Puxionghe fault (referred to as the DLS fault in other literature, e.g., Xu et al. 2003; Zhou et al. 2003) is more active than its northern part. 
The southern transect (EF) cuts across two NW-SE striking faults, North Xiaojiang and Baogunao-Xiaohe. The eastward sub-motion does not change that much when cutting across the North Xiaojiang fault, as it only decreases by $0.4 \mathrm{~mm} \mathrm{yr}^{-1}$ from west to east. We speculate that the North Xiaojiang fault poses a vertical velocity of $0.4 \mathrm{~mm} \mathrm{yr}^{-1}$. Likewise, there appears to be a $4.1 \mathrm{~mm} \mathrm{yr}^{-1}$ displacement velocity change between $\mathrm{H} 108$ and H099. Although there might exist other faults in the middle zone between the North Xiaojiang fault and the Baogunao-Xiaohe fault (e.g., the Qiaojia fault), we still estimate that the eastward velocity change of $4.1 \mathrm{~mm} \mathrm{yr}^{-1}$ may stand for the possible vertical displacement velocity of the Baogunao-Xiaohe fault. Consequently, it should be a transpressive fault, not a pure strike-slip fault that caused the Ludian earthquake disaster.

\subsection{Vertical Velocity Change}

Vertical crustal deformation during an earthquake cycle consists of steady interseismic motion that is punctuated by a coseismic displacement during the earthquake and decaying post seismic deformation (Bürgmann and Thatcher
2013). In our study area the outward expansion of the CDB should be the main source of deformation. Most of the faults are characterized by left-lateral strike slip, and their vertical deformation is not very large. Furthermore, no destructive earthquake occurred in this region (the so-called "earthquake void zone", e.g., Wen et al. 2013). Post-seismic deformation should be small in this area. In order to compare their slip-rate change tendencies, we follow the same three profiles to investigate their vertical change across the NWSE-striking fault system. A positive value represents uplift, and a negative value represents subsidence.

The inner CDB zone shows slow subsidence at present. Station H095 is experiencing a downward tendency at a rate of $-0.3 \mathrm{~mm} \mathrm{yr}^{-1}$ (Fig. 5). To the east, especially at the eastern wall of the Anninghe fault, the vertical velocity is increased by $4.1 \mathrm{~mm} \mathrm{yr}^{-1}$ (Fig. 5). This indicates an uprising movement from west to east. We notice that GPS station H091 is installed in Xide County next to the Xiaoxiang-Ling range (with an average elevation of $>4000 \mathrm{~m}$ ). We interpret that the vertical rate of $1.6 \mathrm{~mm} \mathrm{yr}^{-1}$ at $\mathrm{H} 091$ may represent the minimum uplift rate of the Xiaoxiang-Ling range. A differential uplift rate of $2.2 \mathrm{~mm} \mathrm{yr}^{-1}$ also appears between the
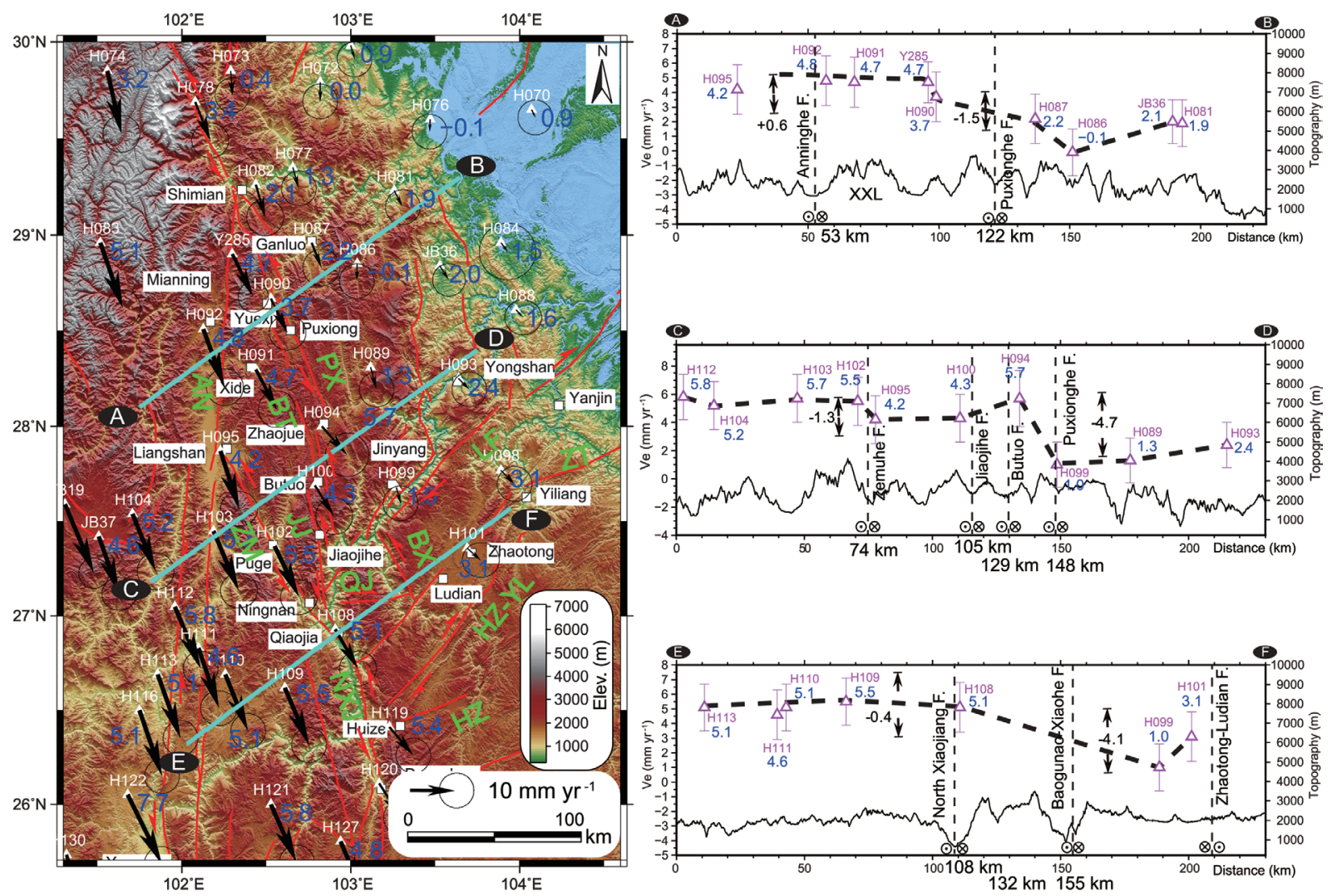

Fig. 4. Horizontal velocity vector synthesis (black arrows) and the eastward velocity subcomponent Ve (blue values) for the east margin of the CDB. The horizontal velocity sectors are referenced with the Eurasia Plate fixed (Gan et al. 2007). AB, CD, and EF are three cross sections perpendicular to the NW-SE striking direction. Their searching swatch width is $\pm 50 \mathrm{~km}$. The bottom black line displays the landform change along the cross section. The relief uses $90 \mathrm{~m}$ SRTM DEM data. AN: Anninghe fault; ZM: Zemuhe fault; NXJ: North Xiaojiang fault; BT: Butuo fault; PX: Puxionghe fault; JJ: Jiaojihe fault; BX: Baogunao-Xiaohe fault; LF: Lianfeng-Jinyang fault; ZT: Zhaotong-Ludian fault; HZ-YL: Huize-Yiliang fault; HZ: Huize fault; QJ: Qiaojia fault. (Color online only) 

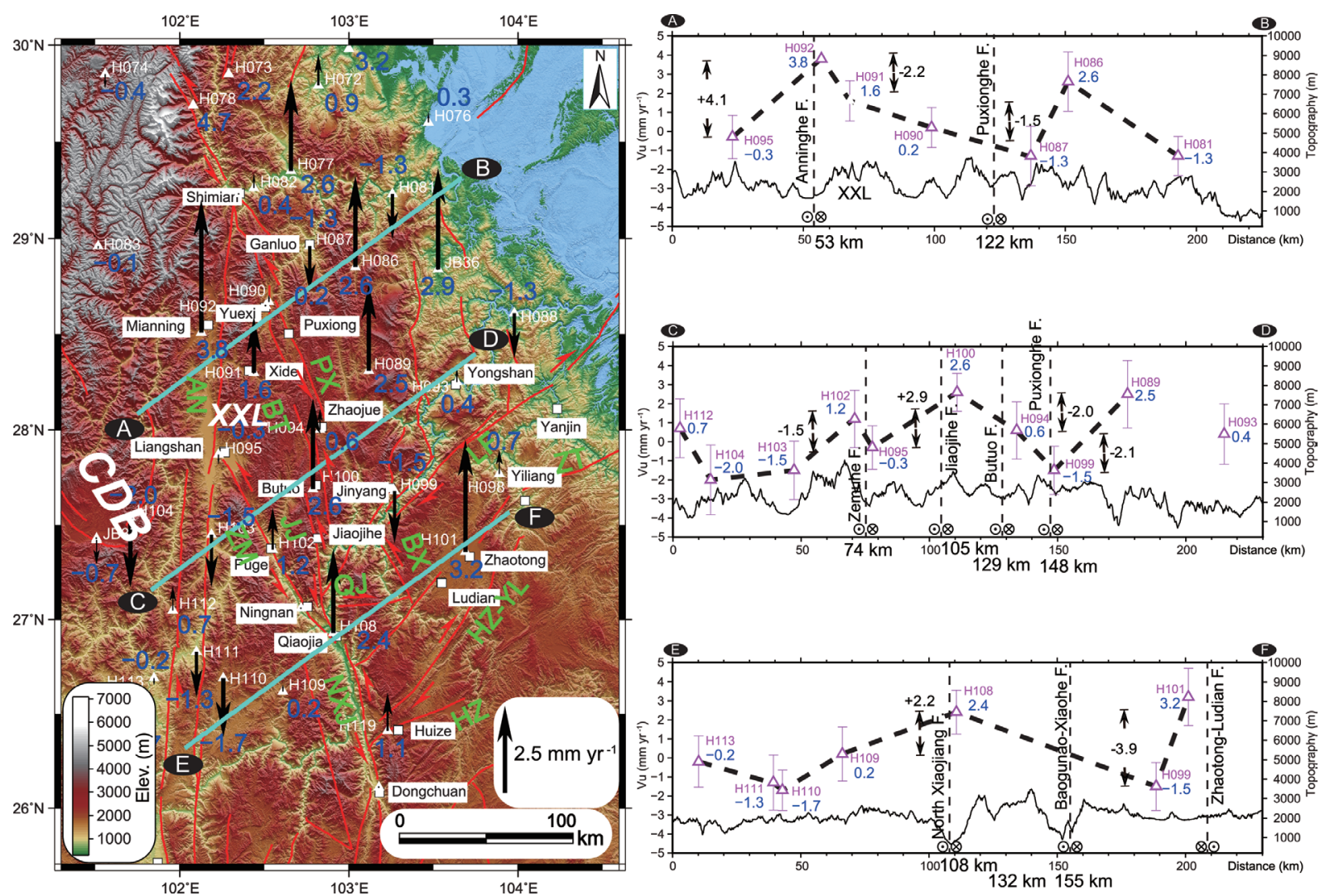

Fig. 5. Vertical velocity field for the east margin of the CDB and the Daliang Shan fault zone. The vertical velocity vectors are also referenced with the Eurasia Plate fixed (Liang et al.2013). AB, CD, and EF are three cross sections perpendicular to the NW-SE striking direction. XXL: XiaoxiangLing range. The search swatch width is $\pm 50 \mathrm{~km}$. The bottom black line displays the elevation change and $90 \mathrm{~m}$ SRTM data are used. Fault names are the same as in Fig. 4. (Color online only)

Anninghe fault and the Xiaoxiang-Ling range (Fig. 5). We further speculate the $2.2 \mathrm{~mm} \mathrm{yr}^{-1}$ also represents a differential uprising rate between the CDB and the Daxiang-Ling range. Farther to the east, a rate difference of $1.5 \mathrm{~mm} \mathrm{yr}^{-1}$ also appears between H090 and H087 (Fig. 5). This indicates that the northern segment of the Puxionghe fault should have a minimum thrusting rate of $\sim 1.5 \mathrm{~mm} \mathrm{yr}^{-1}$.

The vertical velocity is reduced by $\sim 1.5 \mathrm{~mm} \mathrm{yr}^{-1}$ when cutting across the Zemuhe fault (CD profile; Fig. 5). The Zemuhe fault is experiencing a thrusting movement with a rate of $1.5 \mathrm{~mm} \mathrm{yr}^{-1}$. The vertical displacement velocity is increased by $2.9 \mathrm{~mm} \mathrm{yr}^{-1}$ from $\mathrm{H} 095$ to $\mathrm{H} 100$ when cutting across the Jiaojihe fault. The Jiaojihe fault may pose a dipping direction facing to the east. The vertical velocities are gradually reduced by 2.0 and $2.1 \mathrm{~mm} \mathrm{yr}^{-1}$ at the Butuo fault and the southern segment of the Puxionghe fault, respectively (Fig. 5). These dropping rates, 2.0 and $2.1 \mathrm{~mm} \mathrm{yr}^{-1}$, may indicate a thrusting movement rate for the Butuo fault and the southern segment of the Puxionghe fault. Their dipping altitude may face to the west.

The southern section of EF also displays a subsidence tendency inside the $\mathrm{CDB}$, with an average subsidence rate of $\sim 1.5 \mathrm{~mm} \mathrm{yr}^{-1}$. When approaching the North
Xiaojiang fault, the movement changes from subsidence to uplift. There appears to be a $2.2 \mathrm{~mm} \mathrm{yr}^{-1}$ vertical velocity difference between $\mathrm{H} 109$ and H108. The vertical rate change of $2.2 \mathrm{~mm} \mathrm{yr}^{-1}$ may indicate that the North Xiaojiang fault dipping direction is also directed to the west. Because there are only two GPS stations for both sides of the Baogunao-Xiaohe fault, the vertical rate decreases to a total of $3.9 \mathrm{~mm} \mathrm{yr}^{-1}$. The nearly $4.0 \mathrm{~mm} \mathrm{yr}^{-1}$ rate change could not be assigned to only along the Baogunao-Xiaohe fault; however, it could be viewed as an upper limit for the over thrusting rate along this fault. This confirms our speculation that the seismic zone experienced a west-east shortening before the Ludian earthquake.

\subsection{Fault-Parallel and Fault-Normal Rate Change}

If all transpressive faults experience an oblique movement, the rate change should be experienced in the slip-rate change along both the fault-parallel and fault-perpendicular directions. Following this, we decompose the GPS horizontal measurements into fault-parallel and fault-normal directions in order to observe their variations. The three NE-SW cross sections are still used. 


\subsubsection{Velocity Change Along the Anninghe and Puxionghe Faults}

As the striking direction of the Anninghe fault is nearly $\mathrm{N}-\mathrm{S}$, the southward and northward velocities at every GPS station correspond to the fault-parallel and fault-normal slip rates, respectively. The fault-normal rate suddenly increases by $+1.4 \mathrm{~mm} \mathrm{yr}^{-1}$ from H100 to H092 when passing across the Anninghe fault (Fig. 6). A similar decreasing tendency occurs when it meets with the Puxionghe fault with a rate change of $2.9 \mathrm{~mm} \mathrm{yr}^{-1}$ (Fig. 6). We speculate that these two faults have a dip-angle facing west.

The fault-parallel rate along the northern profile $\mathrm{AB}$ is reduced from 13.7 to $7.4 \mathrm{~mm} \mathrm{yr}^{-1}$ when meeting with the Anninghe fault (Fig. 6). The negative sign indicates a displacement to the south. Therefore, the left-lateral strikeslip rate along the Anninghe fault should be $6.3 \mathrm{~mm} \mathrm{yr}^{-1}$. This calculation is consistent with previous research (e.g.,
$6.5 \pm 0.1 \mathrm{~mm} \mathrm{yr}^{-1} ; \mathrm{Xu}$ et al. 2003; Table 1). The fault-parallel rate reduces by $2.0 \mathrm{~mm} \mathrm{yr}^{-1}$ at the Puxionghe fault (Fig. 6). Because the cross section $\mathrm{CD}$ is not strictly perpendicular to the Puxionghe fault striking direction, the drop rate of $2.0 \mathrm{~mm} \mathrm{yr}^{-1}$ is considered to be the minimum left-lateral strike-slip rate for this fault.

\subsubsection{Velocity Change Along the Zemuhe, Jiaojihe, Butuo, and Puxionghe Faults}

The GPS horizontal velocity sectors are decomposed along $\mathrm{N} 135^{\circ} \mathrm{W}$, perpendicular to the striking direction of the Zemuhe fault. The fault-normal rate decreases by $1.2 \mathrm{~mm} \mathrm{yr}^{-1}$ across the Zemuhe fault (Fig. 7). The $1.2 \mathrm{~mm} \mathrm{yr}^{-1}$ rate should be interpreted as the minimum thrusting rate of the Zemuhe fault. To the east the fault-normal rate increases by $2.36 \mathrm{~mm} \mathrm{yr}^{-1}$ at the Jiaojihe fault. This change is consistent with the above analysis for the eastward and

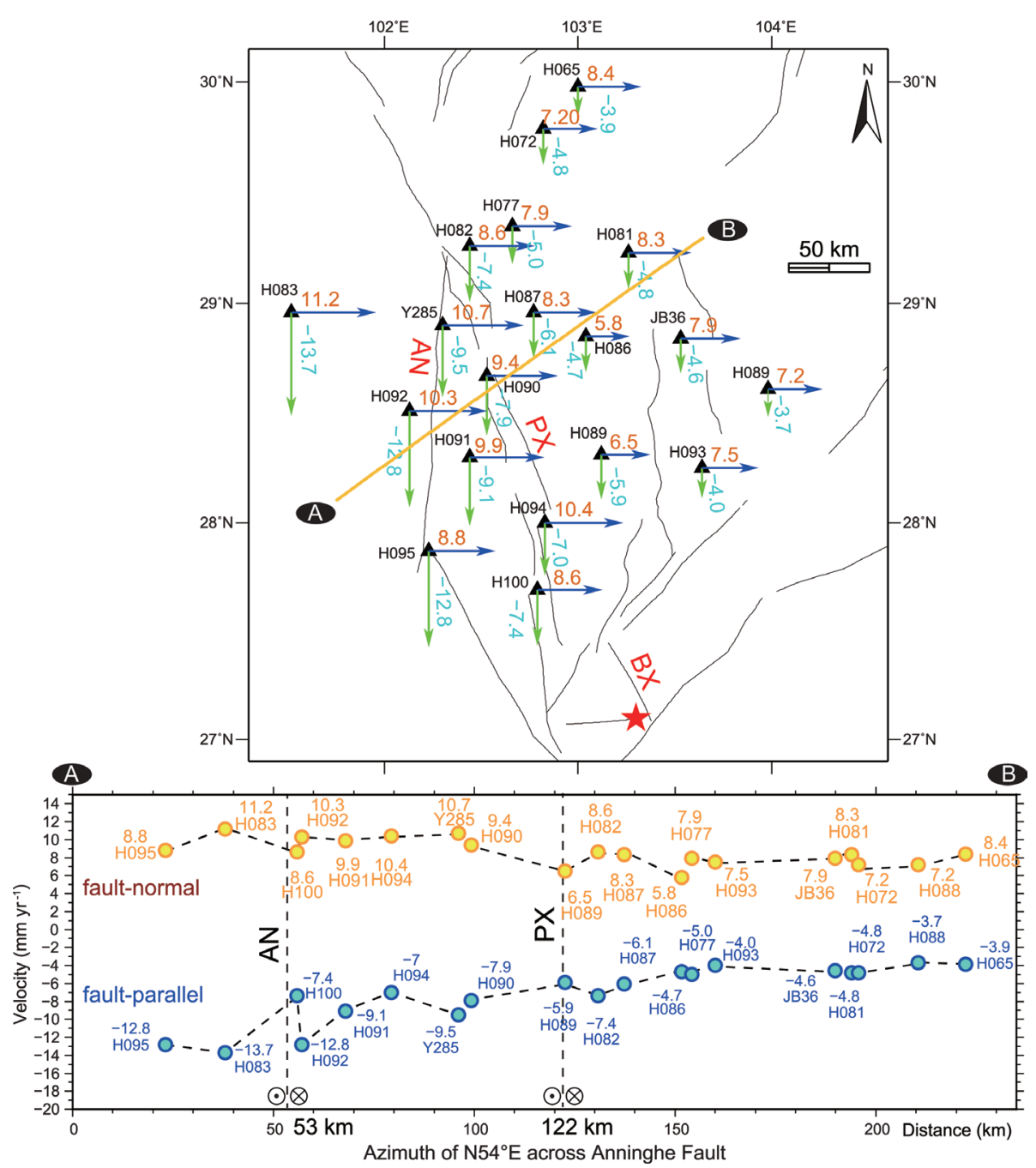

Fig. 6. Map view of GPS velocity vectors for the Anninghe and Puxionghe faults. Velocities are decomposed into fault-parallel (blue) and faultnormal (yellow) movements with Anninghe's strike-slip direction. The yellow line indicates the location for the rate cross section of AB displayed on the bottom. The swath width is 0.5 degree. AN: Anninghe fault; PX: Puxionghe fault. (Color online only) 

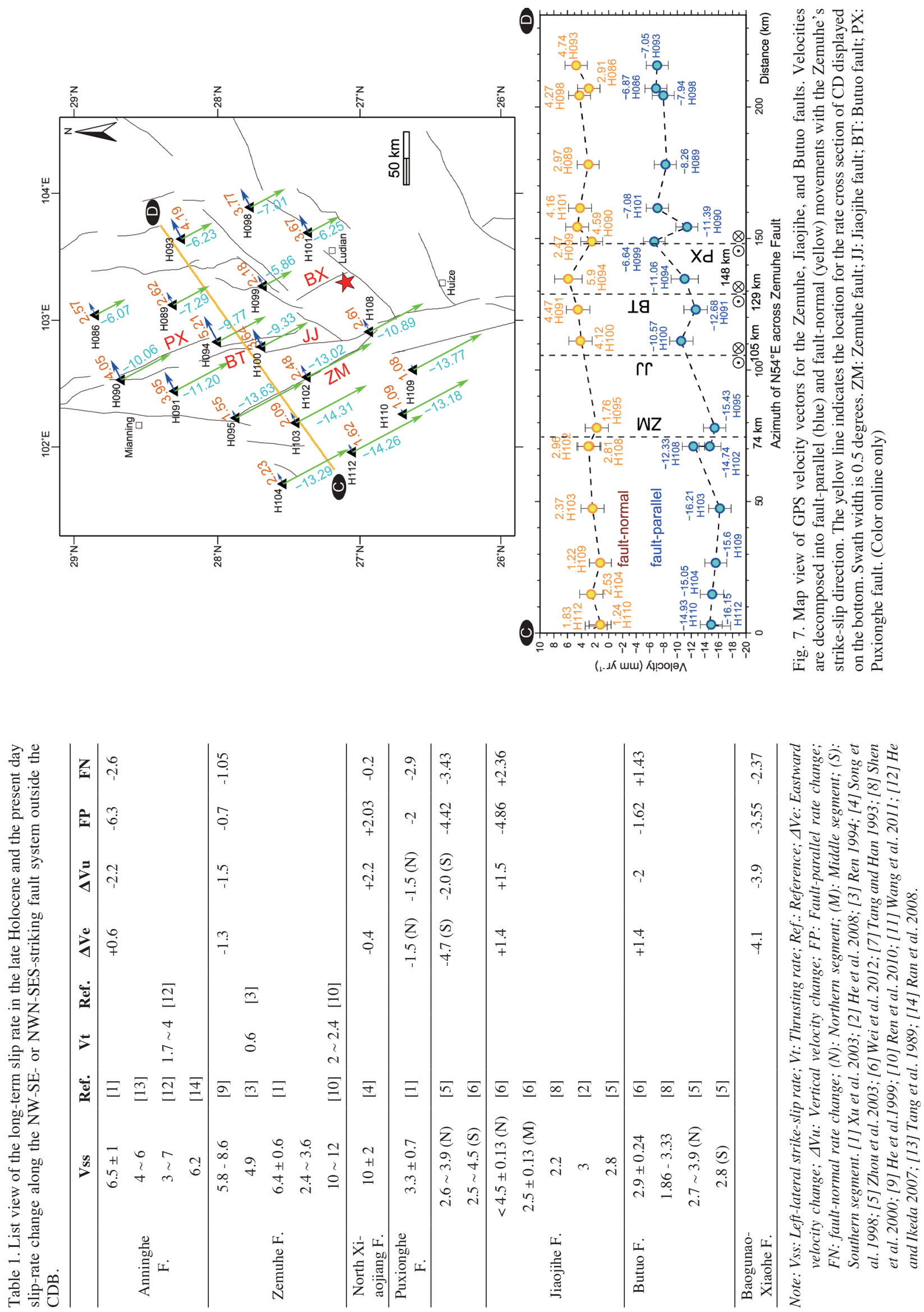
upward velocity change. Thus, the rate change may reflect that the dipping direction of the Jiaojihe fault faces east. Farther to the east, the fault-normal rate at the Puxionghe fault decreases by $2.5 \mathrm{~mm} \mathrm{yr}^{-1}$ from H094 to H099.

The fault-parallel rate is decreased by $0.7 \mathrm{~mm} \mathrm{yr}^{-1}$ at both sides of the Zemuhe fault (Fig. 7). However, the Zemuhe fault is a left-lateral strike-slip fault, so the fault-parallel rate change should increase. One reason for this is that the CD transect is designed to follow a direction perpendicular to the striking direction of the Jiaojihe, Butuo, and Puxionghe faults, not of the Zemuhe fault as that will produce a large bias. Farther to the east the fault-parallel rates are decreased by $4.86,1.62$, and $4.42 \mathrm{~mm} \mathrm{yr}^{-1}$ at the Jiaojihe, Butuo, and Puxionghe faults, respectively (Fig. 7). These dropping rates indicate left-lateral shearing along these three faults.

\subsubsection{Velocity Change at the North Xiaojiang and the Baogunao-Xiaohe Faults}

The GPS velocity vectors along the southern section of $\mathrm{EF}$ are decomposed into a $\mathrm{N} 54^{\circ} \mathrm{W}$ direction, which is normal to the North Xiaojiang striking direction. The faultnormal rate does not change much; however, it is greatly decreased across the two sides of the Baogunao-Xiaohe fault (2.37 $\mathrm{mm} \mathrm{yr}^{-1}$ from H100 to H099; Fig. 8). Although there are only two GPS stations, the decreased rate of $2.37 \mathrm{~mm} \mathrm{yr}^{-1}$ should be the maximum thrusting rate of the Baogunao-Xiaohe fault.

The fault-parallel rate is increased when cutting across the North Xiaojiang fault (e.g., from H119 to H102). That means that the eastern wall is moving to the south. This result is not consistent with our previous knowledge for the North Xiaojiang fault (a left-lateral strike-slip fault). We noticed that the two GPS stations H102 and H119 are situated close to the Huize and Zemuhe faults, respectively (Fig. 8). Their fault-parallel rates may be affected by the activities of these two faults. Farther to the east the southward movement rate at H099 (-6.04 $\left.\mathrm{mm} \mathrm{yr}^{-1}\right)$ is less than that at H100 $\left(-9.59 \mathrm{~mm} \mathrm{yr}^{-1}\right)$. This proves that the Baogunao-Xiaohe fault is also a left-lateral strike-slip fault.

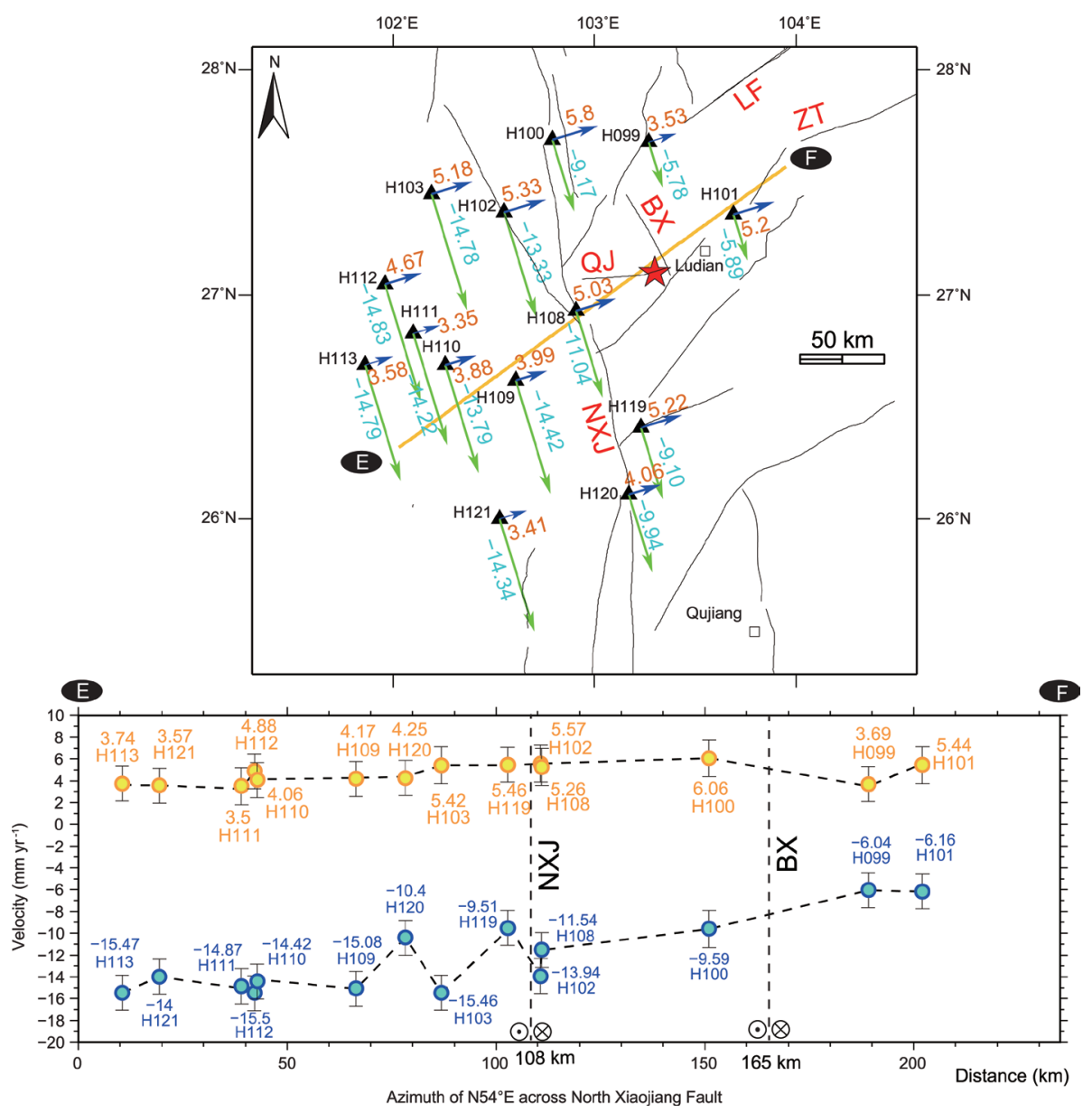

Fig. 8. Map view of GPS velocity vectors for the North Xiaojiang and Baogunao-Xiaohe faults. Velocities are decomposed into fault-parallel (blue) and fault-normal (yellow) movements parallel and perpendicular to the strike-slip direction of the North Xiaojiang. The yellow line indicates the location for the rate cross section of EF displayed on the bottom. The swath width is 0.5 degree. NXJ: North Xiaojiang fault; QJ: Qiaojia fault; BX: Baogunao-Xiaohe fault; ZT: Zhaotong-Ludian fault; LF: Lianfeng-Jinyang fault. (Color online only) 


\section{DISCUSSION}

\subsection{Uncertainty Applying the Slip-Rate Change to Deduce the Vertical Deformation}

The overall motivation for this study was to investigate whether this set of NWW-SES-striking strike-slip faults pose an over thrusting sub-motion, which we believe accommodates the outward expansion of the CDB. However, the resolution of this issue is constrained by the sparse density of GPS measurements, especially the low number of vertical velocity values. Another uncertainty is that the sliprate change is complicated by the asperity distribution of the fault zone at depth, the faulting segmentation on the surface and the far-field effect from plate collision (e.g., East Iran; Berberian et al. 2001; Walker et al. 2010). Even so, this issue is important as it impacts the utility of time-averaged slip-rate estimates in constraining the present-day seismic hazard posed by individual faults.

Table 1 shows the results for the GPS velocity change. Our estimate for the left-lateral strike-slip rate, mainly achieved from the fault-parallel rate change, is smaller in magnitude than the longer-term slip rate (Table 1). The latter rate is calculated with a thousand-year scale, e.g., late Pleistocene and Holocene periods. However, the longer-term slip rates always contain much uncertainty and even errors, since they are deduced from the presence of clearly offset landforms datable by the radiocarbon method. Moreover, the displaced geological body depends more on the subjective judgment of observers in the field. Therefore, whether the thousands-scale variations in slip rate are truly real or are simply artifacts of measurement uncertainties remains far from resolved (e.g., Cowgill 2007; Zhang et al. 2007).
Although the long-term slip rate may result from a switching in activity within a population of faults on timescales of several thousand years, the averaged GPS velocity will not change over the past decade. With this exception, we find that the slip-rate change tendency between the eastward and vertical dimension is the same at the Zemuhe, Puxionghe, Jiaojihe, and Baogunao-Xiaohe faults (see Table 1). By applying a similar variation trend to the comparison result between the fault-normal and vertical slip rates across the Anninghe, Zemuhe, Puxionghe, Jiaojihe, and BaogunaoXiaohe faults (Table 1), the method used in this study has the capability of quantifying the possible transition from eastward expansion to thrusting motion for the CDB.

\subsection{Intersection Angle Among Conjugated Faults: Acute or Obtuse?}

A series of NW-SE left-lateral strike-slip faults is distributed outside the CDB, e.g., the Jiaojihe, Puxionghe, and Baogunao-Xiaohe faults. They intersect with the NE-SW right-lateral strike-slip faults, such as the Zhaotong-Ludian and Lianfeng-Jinyang faults, with an obtuse angle of up to $110^{\circ}$ (Figs. 3a, 9). This case is similar to that within the northern part of the CDB, where a conjugate set of faults has also been reported (Su et al. 2012). The intersection angle, either in the inner or the outer zone, is obtuse. This arrangement pattern of the conjugated fault system is considered to accommodate the E-W shortening and N-S lengthening along the southeast margin of the Tibetan Plateau.

The classical Mohr-Coulomb fracture criterion tells us that the formation angle between a single fault surface and the principle compressional axis $(\sigma 1)$ is commonly $\sim 30^{\circ}$, not

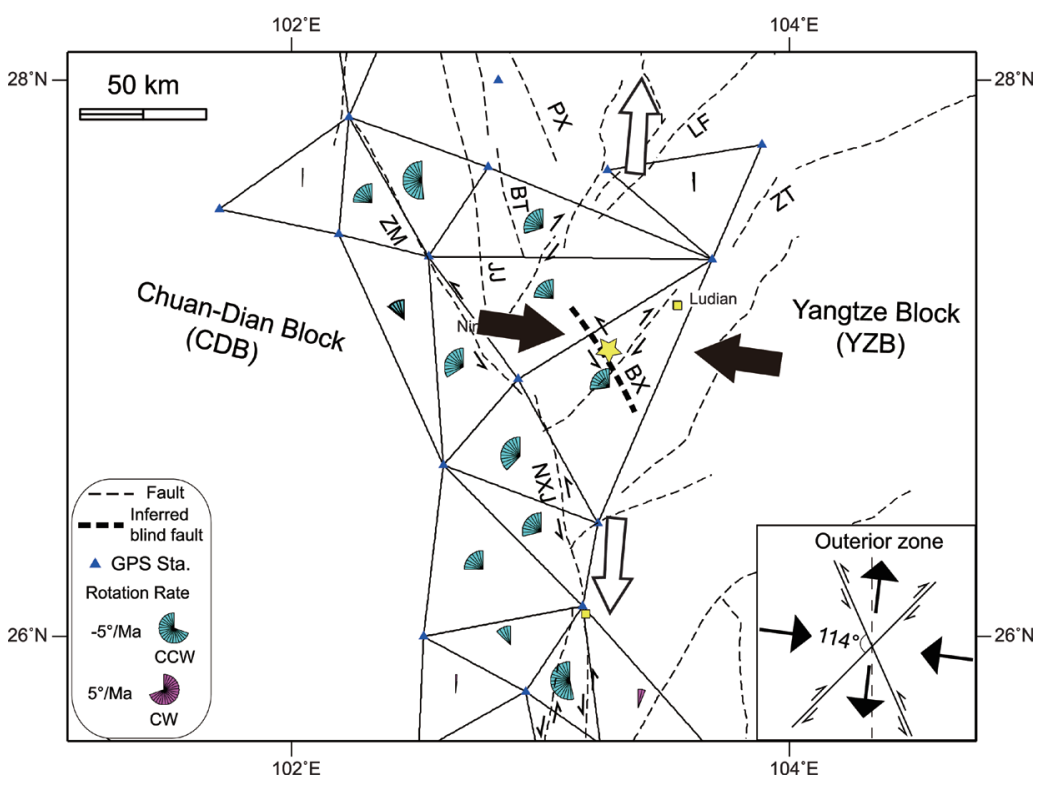

Fig. 9. Rotation strain rate indicated by GPS data. Outside the CDB, the black bold arrow represents the E-W shortening and the white arrow represents extension. (Color online only) 
obtuse. Or, if conjugate faults are present, the angle between the faults is commonly approximated to be $60^{\circ}$ (Price and Cosgrove 1990). Their fracture angles are not acute. Ramsay (1980) interpreted this to mean that the angle between the interacting faults in the direction of maximum compression is originally acute, but as compression proceeds, the conjugate faults rotate so that the angle becomes obtuse and changes from $60^{\circ}$ to greater than $90^{\circ}$.

The recognized conjugated fault system outside the CDB has the same characteristics. The NW-SE-striking leftlateral strike-slip faults intersect with the NE-SW-extending right-lateral faults, also with an obtuse angle up to $114^{\circ}$. To see whether the rotation plays an important role in this, a rotated strain rate is calculated along the east margin of the $\mathrm{CDB}$. The results reveal that a large counterclockwise rotation is widely distributed in the conjugated fault system (Fig. 9). This rotation may affect and even increase the intersection angle of the fault plane in the region. It pushes the fault plane to rotate from the original acute angle into the presently occurring obtuse one. From this perspective, we further speculate that the DLS fault zone is a developing new zone subjected to east-west shortening resulted from the continuous outward expansion of the CDB (He et al. 2008). Accordingly, the CDB is a relatively older geological unit that has experienced a longer E-W shortening history. The CDB may enter a relatively mature evolutionary stage, as a collapsed extensional domain widely prevails in this fragment.

\subsection{How Does the West-East Shortening Occur?}

Many researchers studied the Ludian earthquake using different geophysical methods. Zhang et al. (2014) applied the seismic waveform dataset from far- and near-field seismic stations to get the best fitting solution for the seismogenic structure. The release of seismic energy is mainly focused along the NW-SE striking of the Baogunao-Xiaohe fault. Liu et al. (2014) inverted the regional broadband seismograms to simulate the rupture process. They speculated that the co-seismic rupture process starts from the left-top side of the earthquake source and then proceeds along a NNW-striking structure to move northwestward. However, the above research did not address the following key questions: (1) Which tectonic background accumulated the seismic energy before the Ludian earthquake; (2) How was the previously unfamiliar or even unknown hidden "blind" fault created and activated in an earthquake recycle; (3) What is the relationship between the seismogenic fault (the Baogunao-Xiaohe fault) and its surrounding active faults, e.g., the NWN-SES striking North Xiaojiang fault, the NE-SW extending Zhaotong-Ludian fault.

We try to answer the above questions based on our research results. First, the east-west compressive shortening seems to be caused by the EH wedge-shaped intrusion into SE Tibet. The Ludian seismic zone is just sandwiched in front of the intruding EH to the west and the relatively stable Yangtze Block to the east (Fig. 10). This creates a squeezing stress on its two sides. Second, the CDB's southeastward extrusion is an oblique displacement. This motion could be decomposed into two sub-motions: eastward and southward (Fig. 10). As the Red River-Ailao Shan fault nearly cuts through the whole lithosphere (e.g., Huang et al. 2013), the CDB's southward movement could be resisted by this deeply-cut fault when moving southward (Fig. 10). Consequently, only the eastern side is open for the eastward extrusion of the CDB.

The Ludian earthquake might be related to the outward expansion history of the CDB. No rupture zone has been reported in the Ludian earthquake seismic zone (only several individual geo-cracks were reported by Xu et al.2015). This indicates that, although the Baogunao-Xiaohe fault is the seismogenical structure triggering the Ludian earthquake, it accumulates seismic strain in a silent way and is buried underground. The existence of over thrusting along this invisible fault may also describe a different evolution history for the strike-slip faults in this region. The N-S-striking leftlateral strike-slip faults with minor normal faulting deformation inside the CDB, e.g., the Puduhe, Yimen, and Lvzhijiang faults, may be the older eastern boundary faults of the CDB. An extension environment was created at the back of the spreading-to-the-east CDB. Likewise, the BaogunaoXiaohe fault, together with the other NW-SE-striking leftlateral strike-slip faults such as the Jiaojihe, Butuo, and Puxionghe, will later form a newer and larger scaled eastern

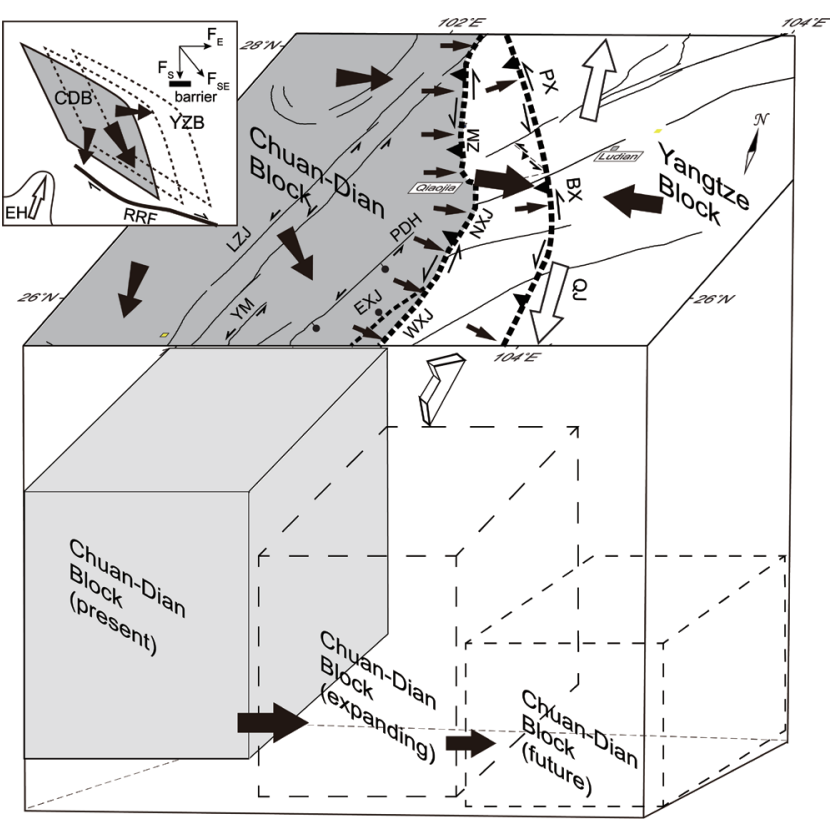

Fig. 10. Illustration of the CDB's eastward expansion. EH: Eastern Himalaya syntaxis; ZM: Zemuhe fault; NXJ: North Xiaojiang fault; EXJ: East Xiaojiang fault; WXJ: West Xiaojiang fault; LZJ: Lvzhijiang fault; YM: Yimen fault; PDH: Puduhe fault. 
CDB boundary. Their eastward over thrusting motion will accommodate the ongoing lateral CDB extrusion.

\section{CONCLUSIONS}

The Baogunao-Xiaohe fault triggered the Ludian earthquake. It is not a pure strike-slip fault, but has an over thrusting sub-motion. In addition, there is a distributed series of NW-SE-striking transpressive faults, e.g., the Zemuhe, Jiaojihe, Butuo, Puxionghe, and North Xiaojiang faults along the east margin of the Chuan-Dian rhombic fragment. They are all left-lateral strike-slip faults with an over thrusting subcomponent and they accommodate the E-W shortening and N-S lengthening outside the Chuan-Dian Block. After analyzing the GPS crustal velocity change, we find that the variations in slip rate along the eastward, fault-normal and vertical dimensions are the same when cutting across the Anninghe, Zemuhe, Puxionghe, Jiaojihe, and BaogunaoXiaohe faults. We speculate that these rate changes may represent a transition from the eastward extrusion of the Chuan-Dian Block to the thrusting motion along these NWSE striking faults.

Acknowledgements This work is supported by the Cross Strait Cooperation Project (Grant No. 4141101073), Youth Program (Grant No. 41502219), and Key Program (Grant No. 41130312) of the National Natural Science Foundation of China, a Self-determined Project (Grant No. 11511270) from the State of Key Laboratory of Lithospheric Evolution, Institute of Geology and Geophysics, Chinese Academy of Sciences, two research grants from Institute of Crustal Dynamics, China Earthquake Administration under (Grant No. ZDJ2013-22 and ZDJ2015-15). Thoughtful advice from three Anonymous Reviewers greatly improved the paper.

\section{REFERENCES}

Berberian, M., J. A. Jackson, E. Fielding, B. E. Parsons, K. Priestley, M. Qorashi, M. Talebian, R. Walker, T. J. Wright, and C. Baker, 2001: The 1998 March 14 Fandoqa earthquake $\left(M_{w} 6.6\right)$ in Kerman province, southeast Iran: Re-rupture of the 1981 Sirch earthquake fault, triggering of slip on adjacent thrusts and the active tectonics of the Gowk fault zone. Geophys. J. Int., 146, 371-398, doi: 10.1046/j.1365-246X.2001.01459.x. [Link]

Bürgmann, R. and W. Thatcher, 2013: Space geodesy: A revolution in crustal deformation measurements of tectonic processes. Geol. Soc. Am. Spec. Pap., 500, $397-$ 430, doi: 10.1130/2013.2500(12). [Link]

Chen, C. Y. and H. L. He, 2008: Crust shortening of Daliangshan tectonic zone in Cenozoic era and its implication. Seismol. Geol., 30, 443-453. (in Chinese)

Chen, G., X. Xu, X. Wen, and Y. Wang, 2008: Kinematical transformation and slip partitioning of northern to east- ern active boundary belt of Sichuan-Yunnan Block. Seismol. Geol., 30, 58-85. (in Chinese)

Chen, Z., B. C. Burchfiel, Y. Liu, R. W. King, L. H. Royden, W. Tang, E. Wang, J. Zhao, and X. Zhang, 2000: Global Positioning System measurements from eastern Tibet and their implications for India/Eurasia intercontinental deformation. J. Geophys. Res., 105, 1621516227, doi: 10.1029/2000JB900092. [Link]

Cowgill, E., 2007: Impact of riser reconstructions on estimation of secular variation in rates of strike-slip faulting: Revisiting the Cherchen River site along the Altyn Tagh Fault, NW China. Earth Planet. Sci. Lett., 254, 239-255, doi: 10.1016/j.epsl.2006.09.015. [Link]

Deng, Q., P. Zhang, Y. Ran, X. Yang, W. Min, and Q. Chu, 2003: Basic characteristics of active tectonics of China. Sci.China Ser. D, 46, 356-372, doi: 10.1360/03yd9032. [Link]

Dixon, T. H., 1991: An introduction to the global positioning system and some geological applications. Rev. Geophys., 29, 249-276, doi: 10.1029/91RG00152. [Link]

Gan, W., P. Zhang, Z. K. Shen, Z. Niu, M. Wang, Y. Wan, D. Zhou, and J. Cheng, 2007: Present-day crustal motion within the Tibetan Plateau inferred from GPS measurements. J. Geophys. Res., 112, B08416, doi: 10.1029/2005JB004120. [Link]

He, H. and Y. Ikeda, 2007: Faulting on the Anninghe fault zone, Southwest China in Late Quaternary and its movement model. Acta Seismologica Sinica, 20, 571583, doi: 10.1007/s11589-007-0571-4. [Link]

He, H., F. Song, and C. Li, 1999: Topographic survey of micro faulted landform and estimation of strike slip rate for the Zemuhe fault, Sichuan Province. Seismol. Geol., 21, 361-369.

He, H., Y. Ikeda, Y. He, M. Togo, J. Chen, C. Chen, M. Tajikara, T. Echigo, and S. Okada, 2008: Newly-generated Daliangshan fault zone--Shortcutting on the central section of Xianshuihe-Xiaojiang fault system. Sci.China Ser. D, 51, 1248-1258, doi: 10.1007/s11430-0080094-4. (in Chinese) [Link]

He, J., S. Lu, and X. Wang, 2009: Mechanical relation between crustal rheology, effective fault friction, and strike-slip partitioning among the Xiaojiang fault system, southeastern Tibet. J. Asian Earth Sci., 34, 363375, doi: 10.1016/j.jseaes.2008.06.003. [Link]

Huang, H. H., Z. J. Xu, Y. M. Wu, X. Song, B. S. Huang, and L. M. Nguyen, 2013: First local seismic tomography for Red River shear zone, northern Vietnam: Stepwise inversion employing crustal $\mathrm{P}$ and $\mathrm{P}_{\mathrm{n}}$ waves. Tectonophysics, 584, 230-239, doi: 10.1016/j.tecto.2012.03.030. [Link]

Huchon, P., X. Le Pichon, and C. Rangin, 1994: Indochina Peninsula and the collision of India and Eurasia. Geology, 22, 27-30, doi: 10.1130/0091-7613(1994)022<00 27:IPATCO >2.3.CO;2. [Link] 
King, R. W., F. Shen, B. C. Burchfiel, L. H. Royden, E. Wang, Z. Chen, Y. Liu, X. Y. Zhang, J. X. Zhao, and Y. Li, 1997: Geodetic measurement of crustal motion in southwest China. Geology, 25, 179-182, doi: 10.1130/0091-7613(1997)025<0179:GMOCMI> 2.3.CO;2. [Link]

Kirby, E. and W. Ouimet, 2011: Tectonic geomorphology along the eastern margin of Tibet: Insights into the pattern and processes of active deformation adjacent to the Sichuan Basin. Geol. Soc. Lond. Spec. Publ., 353, 165-188, doi: 10.1144/SP353.9. [Link]

Kirby, E., K. X. Whipple, B. C. Burchfiel, W. Tang, G. Berger, Z. Sun, and Z. Chen, 2000: Neotectonics of the Min Shan, China: Implications for mechanisms driving Quaternary deformation along the eastern margin of the Tibetan Plateau. Geol. Soc. Am. Bull., 112, 375393, doi: 10.1130/0016-7606(2000)112<375:NOTMS $\mathrm{C}>2.0 . \mathrm{CO} ; 2$. [Link]

Kirby, E., K. Whipple, and N. Harkins, 2008: Topography reveals seismic hazard. Nat. Geosci., 1, 485-487, doi: 10.1038/ngeo265. [Link]

Liang, S., W. Gan, C. Shen, G. Xiao, J. Liu, W. Chen, X. Ding, and D. Zhou, 2013: Three-dimensional velocity field of present-day crustal motion of the Tibetan Plateau derived from GPS measurements. J. Geophys. Res., 118, 5722-5732, doi: 10.1002/2013JB010503. [Link]

Liu, C., Y. Zheng, X. Xiong, R. Fu, B. Shan, and F. Qiao, 2014: Rupture process of Ms 6.5 Ludian earthquake constrained by regional broadband seismograms. Chin . J.Geophys., 57, 3028-3037, doi: 10.6038/cjg20140927. (in Chinese) [Link]

Molnar, P. and K. E. Dayem, 2010: Major intracontinental strike-slip faults and contrasts in lithospheric strength. Geosphere, 6, 444-467, doi: 10.1130/GES00519.1. [Link]

Molnar, P. and P. Tapponnier, 1975: Cenozoic tectonics of Asia: Effects of a continental collision. Science, 189, 419-426, doi: 10.1126/science.189.4201.419. [Link]

Price, N. J. and J. W. Cosgrove, 1990: Analysis of Geological Structures, Cambridge University Press, 520 pp.

Ramsay, J. G., 1980: Shear zone geometry: A review. J. Struct. Geol., 2, 83-99, doi: 10.1016/01918141(80)90038-3. [Link]

Ran, Y., L. Chen, J. Cheng, and H. Gong, 2008: Late Quaternary surface deformation and rupture behavior of strong earthquake on the segment north of Mianning of the Anninghe fault. Sci. China Ser. D, 51, 1224-1237, doi: 10.1007/s11430-008-0104-6. [Link]

Ren, J., 1994: Late Quaternary displacement and slip rate of Zemuhe fault in Sichuan, China. Seismol. Geol., 16, 146. (in Chinese)

Ren, Z., A. Lin, and G. Rao, 2010: Late Pleistocene-Holocene activity of the Zemuhe Fault on the southeastern margin of the Tibetan Plateau. Tectonophysics, 495,
324-336, doi: 10.1016/j.tecto.2010.09.039. [Link]

Schoenbohm, L. M., B. C. Burchfiel, and L. Chen, 2006: Propagation of surface uplift, lower crustal flow, and Cenozoic tectonics of the southeast margin of the Tibetan Plateau. Geology, 34, 813-816, doi: 10.1130/ G22679.1. [Link]

Segall, P. and J. L. Davis, 1997: GPS applications for geodynamics and earthquake studies. Annu. Rev. Earth Planet. Sci., 25, 301-336, doi: 10.1146/annurev. earth.25.1.301. [Link]

Shen, X., Z. Chen, R. Xu, and N. Zhang, 2000: Deformation characteristics and displacement amount of the Liangshan active fault zone in late Cenozoic era. Seismol. Geol., 22, 232-238. (in Chinese)

Shen, Z. K., J. Lü, M. Wang, and R. Bürgmann, 2005: Contemporary crustal deformation around the southeast borderland of the Tibetan Plateau. J. Geophys. Res., 110, B11409, doi: 10.1029/2004JB003421. [Link]

Song, F., Y. Wang, W. Yu, Z. Cao, X. Shen, and J. Shen, 1998: The Xiaojiang Active Fault Zone, Seismological Press, Beijing. (in Chinese)

Su, Z., E. Wang, K. P. Furlong, X. Shi, G. Wang, and C. Fan, 2012: Young, active conjugate strike-slip deformation in West Sichuan: Evidence for the stress-strain pattern of the southeastern Tibetan Plateau. Int. Geol. Rev., 54, 991-1012, doi: 10.1080/00206814.2011.583491. [Link]

Tang, R. and W. Han, 1993: Active faults and earthquakes in Sichuan, China, Seimological Press, Beijing.

Tang, R., Z. Huang, D. Wen, and D. Xia, 1989: A tentative study on the segmentation of the recent motions along the Anning River fault and its relationship with seismicity. J. Seismol. Res., 12, 337-347. (in Chinese)

Tapponnier, P., G. Peltzer, and R. Armijo, 1986: On the mechanics of the collision between India and Asia. Geol. Soc. Lond. Spec. Publ., 19, 113-157, doi: 10.1144/ GSL.SP.1986.019.01.07. [Link]

Tapponnier, P., Z. Xu, F. Roger, B. Meyer, N. Arnaud, G. Wittlinger, and J. Yang, 2001: Oblique stepwise rise and growth of the Tibet Plateau. Science, 294, 16711677, doi: 10.1126/science.105978. [Link]

Thatcher, W., 2003: GPS constraints on the kinematics of continental deformation. Int. Geol. Rev., 45, 191-212, doi: 10.2747/0020-6814.45.3.191. [Link]

Walker, R. T., M. Talebian, R. A. Sloan, A. Rasheedi, M. Fattahi, and C. Bryant, 2010: Holocene slip-rate on the Gowk strike-slip fault and implications for the distribution of tectonic strain in eastern Iran. Geophys. J. Int., 181,221-228, doi: 10.1111/j.1365-246X.2010.04538.x. [Link]

Wang, E., B. C. Burchfiel, L. H. Royden, L. Chen, J. Chen, W. Li, and Z. Chen, 1998: Late Cenozoic XianshuiheXiaojiang, Red River, and Dali fault systems of southwestern Sichuan and central Yunnan, China. Geol. 
Soc. Am. Spec. Pap., 327, 1-108, doi: 10.1130/0-81372327-2.1. [Link]

Wang, E., K. Meng, Z. Su, Q. Meng, J. J. Chu, Z. Chen, G. Wang, X. Shi, and X. Liang, 2014: Block rotation: Tectonic response of the Sichuan basin to the southeastward growth of the Tibetan Plateau along the Xianshuihe-Xiaojiang fault. Tectonics, 33, 686-717, doi: 10.1002/2013TC003337. [Link]

Wang, H., Y. Ran, and Y. Li, 2011: Growth of a small pullapart basin and slip rate of strike-slip fault: with the example of Zemuhe fault on the southeastern margin of the Tibetan Plateau. Seismol. Geol., 33, 818-827, doi: 10.3969/j.issn.0253-4967.2011.04.007. (in Chinese) [Link]

Ward, S. N., 1994: A multidisciplinary approach to seismic hazard in southern California. Bull. Seismol. Soc. Am., 84, 1293-1309.

Wei, Z., H. He, F. Shi, Y. Xu, L. Bi, and H. Sun, 2012: Slip rate on the south segment of Daliangshan fault zone. Seismol. Geol., 34, 282-293, doi: 10.3969/j.issn.02534967.2012.02.007. (in Chinese) [Link]

Wen, X., F. Du, F. Long, J. Fan, and H. Zhu, 2011: Tectonic dynamics and correlation of major earthquake sequences of the Xiaojiang and Qujiang-Shiping fault systems, Yunnan, China. Sci. China Ser. D, 54, 15631575, doi: 10.1007/s11430-011-4231-0. [Link]

Wen, X., F. Du, G. Yi, F. Long, J. Fan, P. Yang, R. Xiong, X. Liu, and Q. Liu, 2013: Earthquake potential of the Zhaotong and Lianfeng fault zones of the eastern Sichuan-Yunnan border region. Chin. J. Geophys., 56, 3361-3372, doi: 10.6038/cjg20131012. (in Chinese) [Link]

Wessel, P. and W. H. F. Smith, 1998: New, improved version of generic mapping tools released. Eos, Trans., $A G U, 79,579$, doi: 10.1029/98EO00426. [Link]

Wilson, C. J. L., M. J. Harrowfield, and A. J. Reid, 2006: Brittle modification of Triassic architecture in eastern Tibet: Implications for the construction of the Cenozoic plateau. J. Asian Earth Sci., 27, 341-357, doi: 10.1016/j.jseaes.2005.04.004. [Link]

Xu, X., X. Wen, R. Zheng, W. Ma, F. Song, and G. Yu, 2003: Pattern of latest tectonic motion and its dynamics for active blocks in Sichuan-Yunnan region, China. Sci.China Ser.D, 46, 210-226, doi: 10.1360/03dz0017. [Link]

Xu, X., C. Xu, G. Yu, X. Wu, X. Li, and J. Zhang, 2015: Primary surface ruptures of the Ludian $M_{w} 6.2$ earthquake, southeastern Tibetan plateau, China. Seismol. Res. Lett., 86, 1622-1635, doi: 10.1785/0220150038. [Link]

Zhang, G., J. Lei, S. Liang, and C. Sun, 2014: Relocations and focal mechanism solutions of the 3 August 2014 Ludian, Yunnan Ms6.5 earthquake sequence. Chin. J.
Geophys., 57, 3018-3027, doi: 10.6038/cjg20140926. (in Chinese) [Link]

Zhang, P. Z., Q. Deng, G. Zhang, J. Ma, W. Gan, W. Min, F. Mao, and Q. Wang, 2003: Active tectonic blocks and strong earthquakes in the continent of China. Sci. China Ser. D, 46, 13-14, doi: 10.3969/j.issn.16747313.2003.z2.002. [Link]

Zhang, P. Z., Z. Shen, M. Wang, W. Gan, R. Bürgmann, P. Molnar, Q. Wang, Z. Niu, J. Sun, J. Wu, H. Sun, and X. You, 2004: Continuous deformation of the Tibetan Plateau from global positioning system data. Geology, 32, 809-812, doi: 10.1130/G20554.1. [Link]

Zhang, P. Z., P. Molnar, and X. Xu, 2007: Late Quaternary and present-day rates of slip along the Altyn Tagh Fault, northern margin of the Tibetan Plateau. Tectonics, 26, TC5010, doi: 10.1029/2006TC002014. [Link]

Zhou, R., X. Li, Z. Huang, Y. He, and T. Ge, 2003: Average slip rate of Daliang Mountain fault zone in Sichuan in Late Quaternary period. J. Seismol. Res., 26, 191-196. (in Chinese)

\section{APPENDIX: DATA AND RESOURCES}

Earthquake catalog data during A.D. 1970 - A.D. 2014 are from China Earthquake Data Center (http://data. earthquake.cn/data/, last accessed August 2015), and data before A.D. 1970 are from the Catalogue of Earthquakes in China (1831 B.C. - A.D. 1969), Chinese Modern Earthquake Catalog (A.D. 1912 - A.D. 1990, Mw 4.7), and Chinese Historical Earthquake Catalog (23 B.C. - A.D. 1911), which are published in Chinese (Gu 1983; Department of Earthquake Hazard Prevention, State Seismological Bureau 1995; Department of Earthquake Hazard Prevention, China Earthquake Administration 1999).

The Global Centroid Moment Tensor Project database was searched using http://www.globalCMT.org/CMTsearch. html (last accessed 11 April 2015).

The U.S. Geological Survey National Earthquake Information Center (USGS NEIC) database was searched using http://earthquake.usgs.gov/earthquakes/search (last accessed 11 April 2015).

The Global Seismic Network database built by the Helmholtz-Centre Potsdam (GFZ) was searched using http://geofon.gfz-potsdam.de/eqinfo/form.php (last accessed 11 April 2015).

The China Earthquake National Center (CENC) historical database was searched using http://www.csndmc.ac.cn/ newweb/data.htm (last accessed 1 January 2015).

The relocation aftershock dataset for the Ludian earthquake is provided in Zhang et al. (2014).

Some of the plots were made using Generic Mapping Tools version 4.5.8 (http://www.soest.hawaii.edu/gmt; Wessel and Smith 1998). 